ISSN 1981-416X

Licenciado sob uma Licença Creative Commons

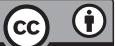

\title{
O Plano Municipal de Educação de Dourados-MS: política, gestão e participação
}

\author{
The Municipal Education Plan in Dourados-MS: political, \\ menagement and participation
}

\section{El Plan Municipal de Educación de Dourados-MS: política, gestión y participación}

\section{Maria Alice de Miranda Aranda, Fábio Perboni, Evally Solaine de Souza Rodrigues*}

Universidade Federal da Grande Dourados (UFGD), Dourados, MS, Brasil

\section{Resumo}

No tempo presente, torna-se indubitável ter como objeto de estudo os Planos de Educação, considerando ser preceito legal no Plano Nacional de Educação (2014-2024) que especifica no Artigo 8o a exigência de elaboração e/ou adequação dos Planos Municipais de Educação no prazo de um ano, contado da publicação da Lei n ${ }^{\circ} 13.005$, de 25 de julho de 2014, que aprovou o Plano Nacional de Educação (2014-2024). Frente ao exposto, este artigo trata do Plano Municipal de Educação (PME) de Dourados no estado de Mato Grosso do Sul (MS) e tem como objetivo analisar seus desdobramentos na gestão das políticas educacionais do

"MAMA: Doutora em Educação, e-mail: mariaaranda@ufgd.edu.br FP: Doutor em Educação, e-mail: fabioperboni@ufgd.edu.br ESSR: Mestre em Educação, e-mail: evallyrodrigues@gmail.com 
município. Para tanto, procedeu-se a revisão bibliográfica sobre o tema e trabalhou-se com a legislação de âmbito federal e municipal e com material produzido pela Comissão Municipal de Monitoramento e Avaliação - CMMA - do PME/Dourados. Os dados apontam que após dois anos de vigência do PME/Dourados-MS a gestão das políticas educacionais do município tem enfrentado dificuldades para estabelecer políticas que estejam em consonância com metas contidas no documento oficial, principalmente com as metas 17 e 18 - que tratam da valorização docente - e a meta 19 - que diz respeito à construção da gestão democrática, ocasionando forte tensão social entre a sociedade civil e a sociedade política.

Palavras-chave: Plano Municipal de Educação. Política e Gestão Educacional. Participação.

\section{Abstract}

Nowadays, it is becoming absolutely necessary to have as the objective of study, the Education Plans, considering that It is legal determination in the National Education Plan (2014-2024) that determinates on the 8th, article the requirement of elaboration and/or adequacy of the Municipal Education Plans at the term of one year, after the publication of the law $n$ 13.005, 25 July 2014, which approved the National Education Plan (2014-2024). After this, this article is about the Municipal Education Plan (PME) of Dourados in the State Mato Grosso do Sul (MS) that has the objective of analyzing its application in the management of the municipal education policies. Hence, the bibliography revision about the theme and worked with the federal and municipal legislation and with material produced by the Commission of Monitoring and Evaluation - CMMA - of PME/Dourados. The information indicates that after two years of validity of the PME/Dourados, the management of educational policies has faced difficulties to support politics that are in agreement with targets contained in the official document, mainly with the aims 17 and 18 - that is about teacher development - and the aim 19 - concerning the construction of democratic management, causing strong social tension between civil society and political society.

Keywords: Municipal Education Plan. Educational management and Policy. Participation. 


\section{Resumen}

En el tiempo presente, se vuelve indudable tener como objeto de estudio los Planes de Educación, considerando ser precepto legal en el Plan Nacional de Educación (2014-2024) que específica en el Artículo 8o la exigencia de elaboración y / o adecuación de los Planes Municipales de Educación en el plazo de un año, contado de la publicación de la Ley no 13.005, de 25 de julio de 2014, que aprobó el Plan Nacional de Educación (2014-2024). En este artículo se trata del Plan Municipal de Educación (PYME) de Dourados en el estado de Mato Grosso do Sul (MS) y tiene como objetivo analizar sus desdoblamientos en la gestión de las políticas educativas del municipio. Para ello, se procedió a la revisión bibliográfica sobre el tema y se trabajó con la legislación de ámbito federal y municipal y con material producido por la Comisión Municipal de Monitoreo y Evaluación - CMMA - de las PYME / Dorados. Los datos apuntan que tras dos años de vigencia de la PYMES/Dourados la gestión de las políticas educativas del municipio ha enfrentado dificultades para establecer políticas que estén en consonancia con metas contenidas en el documento oficial, principalmente con las metas 17 y 18 - que tratan de la valorización docente - y la meta 19- que se refiere a la construcción de la gestión democrática, ocasionando fuerte tensión social entre la sociedad civil y la sociedad política.

Palabras clave: Plan Municipal de Educación. Política y Gestión Educativa. Participación.

\section{Introdução}

Os Planos de educação, seja em nível nacional, estadual ou local, correspondem às formas de planejamento da educação brasileira em sentido amplo, como é o caso dos Planos Municipais de Educação (PME). Segundo Fonseca e Ferreira (2011, p. 70) “o planejamento é uma das estratégias utilizadas para imprimir racionalidade ao papel do Estado e institucionalizar 'as regras do jogo' na administração das políticas governamentais". Analisam, ainda, as autoras, que o planejamento educacional pode ser permeado de concepções várias, que vão desde concepções técnicas às mais participativas. No âmbito educacional o ato de planejar equivale ao processo de abordagem racional e científica para os anseios previstos no 
âmbito da educação, inserindo definições de prioridades e considerando os desdobramentos do cenário educacional (LUCKESI, 2010).

No Brasil, as discussões sobre a necessidade de um instrumento oficial que delineasse os rumos da educação nacional surgiu em 1932 com o "Manifesto dos Pioneiros da Educação Nova", intitulado "A reconstrução educacional no Brasil: ao povo e ao Governo" que pode ser encarado como um projeto nacional de educação de articulação sistêmica e de totalidade. No entanto, foi apenas em 1934 que a ideia de um Plano Nacional de Educação (PNE) tornou-se concreta por meio da promulgação da Constituição Federal (CF/1934), porém com a instituição do Estado Novo, o referido planejamento não passou de mera folha de papel escrita, uma vez que não teve sua efetividade garantida (BORDIGNON, 2011).

Embora a tentativa frustrada de elaborar um planejamento nacional para educação, o anseio de que esse intuito viesse se concretizar não foi barrado pelos descompassos da história. No final da década de 1980 essa ideia ganha força entre defensores da democracia participativa. Então, em 2001 foi aprovado o primeiro Plano Nacional da Educação (PNE) brasileira, porém, não logrou êxito, tanto pela forma que fora elaborado quanto pela ausência de recursos para concretizá-lo, fazendo que esse não passasse de mera letra morta (SAVIANI, 2013).

Mais recentemente, por meio da Lei 13.005, de 25 de junho 2014, ficou estabelecido o Plano Nacional de Educação (PNE) para o decênio 2014-2024, composto por 14 Artigos, 20 Metas e 254 Estratégias. No caso, faz-se destaque para o Artigo $8^{\circ}$, que traz a obrigatoriedade de elaboração dos Planos Municipais de Educação (PMEs), ou a adequação dos Planos dos municípios daqueles que já os tem. Aponta como estratégia para tal empreitada, a necessária articulação das políticas educacionais com as políticas sociais e a garantia de se considerar as necessidades específicas de cada local e da população. No parágrafo $2^{\circ}$ do mesmo Artigo está o indicativo de que a elaboração ou adequação desses Planos deve ser realizada com a participação "de representantes da comunidade educacional e da sociedade civil” (BRASIL, 2014). 
Assim, dando continuidade a pesquisa recentemente concluída intitulada "O Conselho Municipal de Educação (CME) no Brasil e a Qualidade Socialmente Referenciada do Ensino Público" - Chamada Universal - MCTI/CNPq No 14/2014 - que envolveu cinco Universidades Públicas (Universidade Federal de Uberlândia - UFU; Universidade Federal de Goiás - UFG; Universidade Federal da Grande Dourados — UFGD; Universidade Federal de Mato Grosso - UFMT; Universidade do Estado de Mato Grosso - UNEMAT) e, entre outros objetivos, teve o propósito de indagar a participação dos Conselhos Municipais de Educação (CMEs) na elaboração dos Planos Municipais de Educação (PMEs) dos estados brasileiros onde as estas Universidades estão inseridas e está em voga a Pesquisa "Monitoramento dos Planos Municipais de Educação no estado do MS", cadastrada na Pró Reitoria de Pesquisa da UFGD. Ambos com o respaldo teórico de dois Grupos de Estudos e Pesquisas, sendo o primeiro, o Conselho Municipal de Educação no Brasil (GEPCMEBr), com sede na UFU e o segundo "Política e Gestão da Educação", com sede na UFGD.

Monlevade (2013, p. 40) aponta que os Planos de Educação, no caso, os PMEs, precisam oportunizar o pensar a "educação do município como um ser coletivo, que busca sua vocação econômica, que cresce cultural e tecnologicamente, que se expressa como uma comunidade educativa”. Dada a relevância dos Planos para delinear os rumos da gestão da educação nacional para os próximos anos e, por conseguinte a política educacional, esta pesquisa tem como objetivo analisar os desdobramentos do Plano Municipal de Educação de Dourados, no estado de Mato Grosso do Sul (PME/Dourados-MS) na gestão da política educacional local.

Nesses termos, a questão que instiga o estudo em foco é a que segue: Como tem se dado a articulação das políticas locais para atender as estratégias explicitadas no PME/ Dourados-MS? Com intuito de responder à questão recorre-se metodologicamente à pesquisa bibliográfica, fazendo a interlocução com estudiosos do tema numa abordagem dialética; a documental, por meio das seguintes fontes: Constituição Federal Brasileira de 1988 (CF/1988), a Lei de Diretrizes e Base da Educação Nacional de 1996 (LDB), o PNE (2014-2024) e principalmente no PME/ 
Dourados-MS (2015-2025); bem como pesquisa de campo por meio de observação das discussões empreendidas na audiência pública ${ }^{1}$, ocorrida em 10 de maio de 2018, na Câmara Municipal de Dourados-MS, com intuito de aprovar o relatório de monitoramento referente à avaliação bianual do PME/Dourados-MS.

Este artigo está estruturado em três seções. A primeira intitulada o PNE enquanto documento direcionador da política de planejamento educacional; apresenta em linhas gerais a história da constituição da política de planejamento no Brasil. Na segunda seção discute o PME/ Dourados: o processo de formulação e aprovação do documento e busca caracterizar a construção da legislação que institui o PME. A terceira e última seção corresponde à análise dos dados angariados em termos do desdobramento do PME/Dourados-MS (2015-2025) nas políticas educacionais. Por fim, estão delineadas as considerações finais em que os autores tecem criticamente o desfecho das análises.

\section{Do Plano Nacional de Educação (2014-2024) ao Plano Municipal de Educação de Dourados-MS (2015-2025)}

Foi a partir da CF/1988 que o Brasil passou a se constituir em uma República Federativa, cuja concepção de federalismo se insere no sistema de cooperação entre a União e os entes federados. Sistema este também colocado como imperativo legal no PNE (2014-2024) e uma das decorrências foi o chamamento aos municípios com relação à responsabilidade de elaborar ou ajustar seus respectivos planos para a educação. Levando em consideração a trajetória do planejamento educacional no Brasil, considera-se tal exigência necessária, visto relevância do ato de planejar como uma forma de unidade social e política. "Social, porque busca preencher com realizações as promessas e valores que a educação

1 Divulgação da audiência pública por meio da imprensa digital: <http://www.folhadedourados.com. br/noticias/dourados/relatorio-de-avaliacao-do-pme-sera-apresentado-em-audiencia-nesta-5>. 
encerra. Política, porque em países federativos há que haver um equilíbrio entre unidade nacional e diversidade regional" (CURY, 2013, p. 32).

No caso brasileiro, um plano de educação, além de se impor como medida racional de maximização dos recursos, objetiva ser uma "baliza de frente" (CURY, 2013, p. 32) a fim de que os princípios educacionais traduzam-se em políticas consistentes tendo por base um rigoroso diagnóstico dos problemas educacionais.

Nessa direção, Saviani (2014) ressalta a relevância do planejamento em educação, uma vez que o plano educacional se apresenta como o instrumento que pretende introduzir racionalidade na prática educativa a fim de superar o espontaneísmo e as improvisações que são o oposto de uma educação sistematizada. Pondera-se que o planejamento se mostra como uma ferramenta de intervenção no processo de implementação de políticas públicas, de forma a prover orientações gerais e fundamentos técnicos essenciais à tomada de decisões.

Frente ao exposto, nota-se por meio do PNE (2014-2024) a ratificação da relevância do planejamento educacional, tanto na esfera federal quanto estadual e municipal, uma vez que a própria Lei n 13.005/2014 estabelece o prazo e a obrigatoriedade da elaboração dos planos pelos sistemas regionais e locais de educação, bem como a criação de mecanismos de monitoramento e avaliação do respectivo documento. Assim sendo, avança-se para os principais pontos que marcaram o processo de formulação do PME/Dourados-MS (2015-2025).

De início, cabe registrar que o município de Dourados está situado no sul da região Centro-oeste, no sudeste do estado de Mato Grosso do Sul (MS), a 253 km de distância da capital do estado, Campo Grande. Dourados conta com 4.096,90 km de extensão territorial e é habitado por 196.035 pessoas, com estimativa de 218.069 habitantes para o ano de 2017, que o torna o segundo município mais populoso do estado e o $136^{\circ}$ do país (IBGE, 2010).

De acordo com o censo do IBGE de 2015 o número de instituições educativas pertencentes ao município de Dourados corresponde a 82 Creches Municipais do Ensino Infantil (CMEI), sendo 68 centros de educação infantil pública, administrada pelo poder municipal; e 14 privadas. 
79 escolas de ensino fundamental, sendo 45 instituições educativas vinculadas à administração municipal, 22 ao poder estadual e 12 escolas privadas. Referente ao ensino médio, o município conta com 18 escolas públicas estaduais e sete instituições privadas, totalizando 25 unidades educativas voltadas para esse nível de ensino (IBGE, 2015).

Em 2015 registrou-se 4.948 matrículas na educação infantil do município de Dourados, sendo 3.473 efetivadas na esfera pública de ensino e 1.475 nas instituições particulares. No ensino fundamental das 33.488 matrículas realizadas 19.165 foram feitas em escolas municipais, 9.963 em escolas estaduais e 4.360 na esfera privada. Com quantitativo menor, as matrículas no ensino médio chegaram a 7.157, sendo 5.908 na rede estadual e 1.249 em escolas particulares.

Em relação ao campo universitário, Dourados tem o título de "Cidade Universitária" por comportar a Universidade Federal da Grande Dourados (UFGD), Universidade Estadual de Mato Grosso do Sul (UEMS), o Centro Universitário da Grande Dourados (UNIGRAN) e a Faculdade Anhanguera de Dourados, além da unidade do Instituto Federal de Educação do Mato Grosso do Sul (IFMS) e da Faculdade de Tecnologia do SENAI (FATEC-SENAI).

Além dos dados estatísticos, nos últimos anos, Dourados tem chamado atenção pelos entraves no âmbito da gestão do sistema municipal de ensino, resultando em uma luta histórica empreendida entre a sociedade civil, sobretudo os profissionais da educação, e a sociedade política, o poder público local, em prol do direito à educação pública, gratuita e de qualidade. Embates esses que tem fomentado as discussões acerca dos desdobramentos do PME/Dourados-MS.

O PME/Dourados-MS referente ao decênio de 2015 a 2025 corresponde a segunda tentativa de elaboração de um documento com função basilar para as políticas educacionais local. A primeira tentativa se desencadeou no ano de 2002 em decorrência da visibilidade que a política de planejamento da educação alcançou no Brasil em virtude da Lei 10.172 (PNE/2001-2011).

No entanto, assim como a maioria dos municípios brasileiros, o PME/ Dourados-MS do início do milênio não logrou êxito. A esse respeito Dourados (2002, p. 685) ressalta: 
[...] a aprovação de planos estaduais e municipais, previstos no PNE como base para a sua organicidade, não se efetivou como política concreta na maior parte dos estados e municípios, e, desse modo, tal processo não contribuiu para o avanço na dinâmica de democratização do planejamento e da gestão da educação no país e para a ratificação do Plano como política de Estado.

Os motivos que levaram a política de planejamento da educação nacional do início dos anos 2000 ao fracasso são diversos, tais como as questões orçamentárias, carência de um sistema de avaliação e monitoramento capaz de orientar o plano, ausência de legislações que dessem suporte para efetivação dos Planos e, sobretudo, a cultura política nacional que de acordo com Saviani (2013) tende a ser avessa ao planejamento pautado na racionalidade inerente à ação planejada.

Desse modo, os Planos de educação referentes à primeira tentativa pós Constituição Federal de 1988 “[...] não passou de uma carta de intenções, pois a lei que o instituiu permaneceu letra morta, sem nenhum influxo nas medidas de política educacional e na vida das escolas" (SAVIANI, 2013, p. 11).

Em relação ao município de Dourados a primeira tentativa de elaboração do PME contou com dois momentos distintos. A primeira ocasião foi marcada pela atuação da Secretaria de Municipal de Educação (SEMED) no intuito de fomentar a participação popular na discussão das metas e estratégias do documento, porém, o grande entrave foi à dificuldade para elaborar propostas concretas (DOURADOS, 2002).

O segundo momento ocorreu em 2003 após reestruturações político-administrativas do município, principalmente a troca de prefeito, que culminou no enfraquecimento do movimento participativo de construção coletiva do PME, resultando no engavetamento do rascunho da proposta inicial. Analisa Dourado (2007) que a constituição e a trajetória histórica das políticas educacionais no Brasil, bem como e os processos de organização e gestão da educação nacional, são marcados "hegemonicamente pela lógica da descontinuidade, por carência de planejamento de longo prazo que evidenciasse políticas de Estado em detrimento de políticas conjunturais de governo" (p. 925). 
A segunda tentativa de construção do PME no município de Dourados ocorreu em 2014 visando atender o Art. 8 . Essa obrigatoriedade ratificada no PNE (2014-2024) resultou no PME/Dourados-MS (2015-2025). O documento local foi instituído pela Lei municipal n ${ }^{\circ} 3.904 / 2015$ que possui 14 artigos e apresenta anexo único contendo 20 metas e 254 estratégias.

As discussões acerca da organização do PME/Dourados-MS (2015-2025) iniciaram em 15 de abril de 2014 com a primeira reunião que teve como objetivo debater os seguintes assuntos sobre o PME: organização do calendário, elaboração do regimento interno, plano de ação de trabalho, entre outras questões (DOURADOS, 2015).

Para dar andamento ao processo de elaboração do PME, no dia 24 de abril de 2014 foi publicado no Diário Oficial n 3.712 por meio da Resolução $n^{\circ}$ 21/2014 a relação dos representantes da sociedade civil e da SEMED que integrariam a comissão responsável pela redação do Plano.

Conforme consta na redação de apresentação do PME inicialmente o Plano foi redigido por seis subcomissões, fazendo referência estrita as metas contidas no PNE (2014-2024). O texto primeiro foi apresentado à sociedade civil no dia 25 de agosto de 2014 na Câmara Municipal de Dourados. A partir de então, desencadearam por 18 meses as discussões e construção do documento.

No entanto, para a surpresa da comunidade escolar e os diversos segmentos que participaram ativamente do processo de elaboração do PME, o documento enviado para votação no legislativo não foi o mesmo que resultou da assembleia final de construção do Plano, pois ficou constatado que 71 das 376 estratégias elaboradas pelos profissionais da Educação e entidades da sociedade foram retiradas do documento sem nenhum aviso prévio. Além disso, outras tantas foram modificadas, a maioria retirando prazos para o cumprimento de metas e suprimindo itens que são reivindicações antigas dos profissionais de Educação do município (SIMTED/Dourados, 2015).

Aranda (2018), em sua pesquisa sobre a valorização docente dentro da política de planejamento do município de Dourados, ressalta que o sufocamento das proposições iniciais do PME resultou em uma série de protestos 
e ganhou forte repercussão nos jornais locais impressos e eletrônicos, causando prejuízo à imagem dos vereadores que votaram a favor da aprovação do documento alterado. Em represália, esses parlamentares entraram com ação judicial contra o Sindicato dos Trabalhadores em Educação da cidade (SIMTED), que encarou o processo com tranquilidade e sem deixar que esse acontecimento silenciasse a luta pelo direito de participação efetiva.

Ocorreu no ano de 2017 por meio do Decreto n 363, de 05 de junho, a nomeação da Comissão Municipal de Monitoramento e Avaliação do Plano Municipal de Educação de Dourados - CMMA-PME e Equipe Técnica, considerando a Lei Federal 13.005, de 25 de junho de 2014 que aprovou o PNE (2014-2024) e a Lei Municipal 3.904/2015, que aprovou o PME/Dourados, MS, com a finalidade de orientar e coordenar o processo de monitoramento e avaliação do PME, bienalmente (Dourados, 2017). O primeiro relatório de avaliação foi apresentado em 10 de maio de 2018 em Audiência Pública realizada na Câmara Municipal de Dourados. E os desdobramentos do PME/ Dourados-MS (2015-2025) nos últimos dois anos na construção das políticas públicas para a educação local materializam a seção que segue.

\section{O desdobramento do PME/Dourados-MS (2015- 2025) na política educacional}

O PME/Dourados-MS (2015-2025) enquanto documento legal da gestão educacional municipal, que conforme imperativo legal dado pelo Plano Nacional de Educação (2014-2024) pode ser concebido a partir do referencial de Palumbo (1998) o qual explicita que uma determinada política educacional não pode ser apenas observada, tocada ou sentida, não se trata de um único evento ou uma única decisão, mas sim de um conjunto de ações que se complementam. Assim, política é referenciada como: "[...] um processo, uma série histórica de intenções, ações e comportamentos de muitos participantes" (p. 35).

Conforme sinalizado anteriormente, o PME/Dourados-MS possui 20 metas e 254 estratégias para a educação municipal dos próximos 
anos (até 2025). Considerando que em cada meta residem particularidades, nesta pesquisa o enfoque recairá sobre as metas 17, 18 e 19, visto os desdobramentos que o teor desses objetivos tem fomentado na política local.

Segundo o PME/Dourados-MS (2015-2025) a Meta 17 pretende valorizar os profissionais do magistério das redes públicas de educação básica de forma a equiparar seu rendimento médio ao dos demais profissionais com escolaridade equivalente, até o final do sexto ano de vigência deste PME (DOURADOS, 2015, p. 39).

Transcorridos mais de dois anos da publicação do PME/Dourados, a CMMA empreendeu nos anos de 2017 e 2018 o monitoramento e a avaliação das metas contidas no Plano. No tocante à meta 17 , o relatório de avaliação aponta que $47 \%$ dos profissionais em educação do município de Dourados já alcançaram o previsto na meta 17; porém, cabe salientar que os dados utilizados para quantificar esse percentual são oriundos de informações da própria administração local, isto é, não provém do censo oficial. Segundo relato da Coordenadora da CMMA-PME/Dourados-MS, proferido na apresentação do relatório em Audiência Pública na Câmara Municipal de Dourados, a carência de dados oficiais atualizados, bem como instrumentos de coletas voltados para o levantamento de informações específicas, tem dificultado o trabalho de avaliação da situação educacional do município.

Quanto à remuneração dos professores da Rede Municipal de Educação de Dourados (REME/Dourados), um levantamento empreendido no ano de 2017 pelos sindicatos do estado aponta com base no ranking salarial divulgado pela Federação dos Trabalhadores em Educação do Mato Grosso do Sul (FETEMS) mostra que Dourados ocupa a $69^{\circ}$ posição no ranking salarial do magistério público, considerando os $79 \mathrm{mu}$ nicípios que o estado possui (SIMTED, 2017). Desse modo, concorda-se com Aranda (2018) quando afirma que essa colocação em que a cidade de Dourados se encontra no ranking salarial não é compreensível, visto a existência de dezenas de municípios menores, com receitas inferiores e ainda assim remuneram melhor seus servidores.

Após um biênio da aprovação do PME/Dourados, a categoria docente luta pela quitação do reajuste salarial referente aos anos de 2017 e 2018. 
Segundo o SIMTED a categoria vem tentando estabelecer um diálogo com a administração municipal há meses, porém sem sucesso.

No ano de 2017 a categoria lutava pela correção salarial de $7,64 \%$. Sem respostas concretas por parte da prefeitura os professores do município decidiram em assembleia, no mês de agosto de 2017, deflagrar greve. No entanto, a administração municipal entrou com liminar no Tribunal de Justiça de Mato Grosso do Sul (TJMS), pelos Autos $n^{\circ}$ 1409279-25.2017.8.12.0000, solicitando o fim da paralisação.

A ação foi acatada pelo TJMS, determinando que ao menos $66 \%$ dos docentes retomassem o exercício de suas funções, caso contrário incidiria a penalidade de $\mathrm{R} \$ 50.000,00$ (cinquenta mil reais) de multa diária. A decisão foi publicada em Diário Oficial por meio da Resolução/SEMED nº 074 de 19 de agosto de 2017. Dada a circunstância, a categoria decidiu substituir a greve geral pela parcial, somente $34 \%$ dos docentes participaram diretamente da greve.

Sob forte pressão por parte do poder público e da sociedade civil, os (as) professores (as) se viram obrigados a retomar suas atividades, extinguindo o movimento grevista daquele ano, porém, transcorrido 12 meses desde a data do primeiro reajuste não cumprido, a categoria tenta novamente estabelecer um diálogo com o poder público que até o momento (maio de 2018) não obteve sucesso, conforme informativo registrado pelo SIMTED da tentativa, há meses, de solicitação de reuniões com o governo municipal para tratar da reposição salarial do Piso Nacional e Municipal dos Professores e reposição anual do grupo administrativo, que estão sem o reajuste do ano de 2017 e presenciam mais uma data base vencer sem uma proposta real da prefeitura (SIMTED/Dourados, 2018).

Além da carência de reajuste salarial, a categoria docente do município de Dourados enfrentou no final do ano 2017 e início de 2018 a ausência integral de seus respectivos vencimentos, do $13^{\circ}$ salário, bem como a redução salarial; resultando em uma política de escalamento para tentativa de quitação salarial: "Segundo a administração, somente quem recebe até $\mathrm{R} \$ 2.250,00$ líquidos deverá receber o salário no primeiro momento. Essa prática, adotada pela prefeitura há meses, tem gerado inúmeros transtornos aos profissionais da Educação." (SIMTED/Dourados, 2018). Registra-se 
ainda "[...] informações de alguns profissionais dão conta de que há erros em valores de remunerações recebidas ainda no mês de novembro. Em outros casos, profissionais estariam ainda sem receber o décimo terceiro salário" (SIMTED/Dourados, 2018).

As políticas públicas se traduzem perfeitamente por meio das ações que se materializam em processos, em que lutas são empreendidas e grupos em conflitos influenciam na agenda governamental. Para Martins (2014) a etapa de maior relevância de uma política está no processo de implementação, visto que é nesse contexto que as políticas ganham dinâmica, mudam, são reorientadas e renegociadas.

A efetivação da meta 18 também tem apresentado alguns entraves, considerando que essa objetiva:

[...] assegurar, no prazo de 2 (dois) anos, a existência de planos de Carreira para os profissionais da educação básica e superior pública de todos os sistemas de ensino e, para o plano de Carreira dos profissionais da educação básica pública, tomar como referência o piso salarial nacional profissional, definido em lei federal, nos termos do inciso VIII do art. 206 da Constituição Federal (DOURADOS, 2015, p. 40).

Dourados, MS possui Plano de Cargos, Carreira e Remuneração (PCCR), instituído legalmente pela Lei Complementar n 118 de 31 de Dezembro de 2007. Os entraves nessa estratégia correspondem à efetivação da valorização docente que após a aprovação do Plano as ações da administração municipal tem se distanciado das estratégias contidas na respectiva meta. Após o segundo semestre de 2017 o poder público municipal iniciou um processo de atualização nos PCCRs dos servidores. No entanto, essa ação resultou no descontentamento da categoria com a administração local, visto a ausência de diálogo e a supressão de direitos.

Depois de duas tentativas o legislativo municipal aprovou a Lei complementar $n^{\circ} 13 / 2017$, em que "[...] a política salarial dos professores/as apenas se transformou em gratificação, trazendo insegurança jurídica para os/as profissionais". Além disso, "A lei ainda condiciona o pagamento da incorporação - a qual, neste mês de outubro, deveria ter sido 
pago o valor de $1 / 4$ da diferença entre o Piso Municipal e o Piso Nacional dos/as Professores/as - ao recebimento de recurso do Pré-Sal, que os municípios não devem mais receber" (SIMTED/Dourados, 2017).

O processo de reformulação do PCCR foi marcado por intensas manifestações e protestos pacíficos empreendidos pela categoria docente, porém, além de ser reprimida por meio da intimidação policial, a categoria não conseguiu ao menos estabelecer um diálogo com o poder público, uma vez que para os profissionais em educação o projeto foi aprovado de forma autoritária e sem tentativa de negociação (SIMTED/Dourados, 2017).

A política educacional não é neutra, mas carregada de significados, por meio da forma como são organizadas e implementadas pela sociedade política e pela sociedade civil, denota a concepção de sociedade que se pretende formar (SCHNECKENBERG, 2000). Nessa direção, Azevedo (1997, p. 59-60) define a política educacional no rol das políticas públicas, portanto o "Estado em Ação", cuja implantação se dá por meio de programas, projetos, planos, voltados para setores específicos da sociedade e por eles implementados.

Ao analisar as metas 17 e 18, percebe-se que a administração municipal além de organizar a gestão do município de forma alheia à democracia participativa, também se distancia do que fora pensado e planejado ao longo da construção do PME/Dourados, desconsiderando sua função basilar para elaboração de políticas públicas.

Cabe salientar que a valorização docente corresponde a um dos elementos essenciais na construção do ensino de qualidade, por isso, é imprescindível o reconhecimento dos profissionais do magistério, pois a "[...] qualidade da educação e valorização profissional devem caminhar juntas [...] é necessário, dar sequência às políticas voltadas para a educação como direito" (VIEIRA, 2016, p. 41).

A meta 19, assim como as demais, segue com a mesma redação do PNE (2014-2024) e do Plano Estadual de Educação de Mato Grosso do Sul (PEE/MS 2014-2024), logo pretende:

[...] assegurar condições, no prazo de 2 (dois) anos, para a efetivação da gestão democrática da educação, associada a critérios técnicos de 
mérito e desempenho e à consulta pública à comunidade escolar, no âmbito das escolas públicas, prevendo recursos e apoio técnico da União para tanto (DOURADOS, 2015, p. 42).

Ao analisar essa meta, percebem-se duas questões elementares e preocupantes para a verdadeira construção democrática dentro das instituições escolares. A primeira corresponde à compreensão de gestão democrática restrita a eleição de diretores. É fato que a escolha dos gestores escolares por meio da comunidade representa um instrumento de gestão participativa, porém, a organização escolar democrática requer a implementação de uma série de mecanismos que levem as pessoas participarem de fato, isto que adquiram poder e desenvolvam a consciência crítica.

O segundo ponto paradoxal está na "[...] efetivação da gestão democrática da educação, associada a critérios técnicos de mérito das escolas públicas [...]" (DOURADOS, 2015, p. 42, grifo dos autores). Esse trecho traduz exatamente a lógica capitalista para dentro da educação, uma vez que é característico da democracia liberal prezar pelo individualismo e a liberdade. A igualdade de oportunidades se expressa na argumentação despropositada de "segundo a capacidade de cada indivíduo, e não a igualdade real na sociedade" (VIEIRA, 1992, p. 70).

Desse modo, no final do ano de 2017, mais de dois anos de aprovação do PME/Dourados, começou-se a organização por parte do poder executivo e legislativo do município para a construção do Projeto de Lei que acabasse com as eleições para diretores escolares da Rede Municipal de Ensino (REME), o que fora considerado um retrocesso, visto que muitos municípios do estado, após aprovação do Plano, têm empreendido ações para findar o sistema de indicação e outras formas antidemocráticas para seleção de gestores escolares.

É fato que conforme Dourado (2001) afirma a forma de provimento do cargo de diretor escolar não tenha o poder de definir o tipo de gestão, mas certamente interfere no curso desta, logo a escolha democrática não garante uma gestão participativa, mas oportuniza a aproximação da comunidade a escola por meio da participação. 
Dado a compreensão da relevância do direito de escolha do gestor escolar a comunidade civil, bem como a comunidade escolar e a categoria manifestaram intensamente contra essa pretensão governamental; tomando grande proporção nos meios de comunicação, o que fez o poder público recuar com a proposta.

\section{Considerações finais}

As contribuições possibilitadas pelo estudo e relacionadas aos conhecimentos angariados pelas pesquisas supramencionadas oportunizou tecer discussão sobre os rumos da gestão do planejamento da educação municipal por meio do objetivo que buscou analisar os desdobramentos do PME/Dourados-MS na gestão da política educacional local.

Nessa direção, ao analisar os desdobramentos decorrentes do PME/Dourados-MS, sistematizados pela Comissão Municipal de Monitoramento e Avaliação do mesmo, os dados apontam que após dois anos de vigência do Plano, a gestão das políticas educacionais do município tem enfrentado dificuldades para estabelecer políticas que estejam em consonância com metas contidas no documento oficial, principalmente com as metas 17 e 18, que tratam da valorização docente e a meta 19, que diz respeito à construção da gestão democrática, ocasionando forte tensão entre a sociedade civil e a sociedade política, numa demonstração que ainda há distância, considerando o social, o político, o econômico, para o alcance de suas principais metas, rumo a concretização de uma política educacional de caráter estatal.

Entende-se que políticas de Estado são aquelas que encontram sustentação social, política e financeira no espaço para o qual são destinadas, diferentemente de políticas de governo que duram apenas enquanto determinado governo está no poder, atendendo a propósitos pontuais e particulares, portanto, a sustentação é apenas aparente. 
Além disso, entende-se que, para um Plano de Educação se tornar uma política de Estado, depende-se da concepção de planejamento, de gestão, de Estado, uma vez que a concepção ou as concepções presentes podem servir a objetivos vários. Portanto, nem sempre o entendimento que os sujeitos da educação têm quanto à própria educação, à sociedade, a ser humano é compreendido, mesmo que em meio às contradições presentes no sistema social vigente.

É nesse sentido que se primou por deixar evidente nesse estudo que a política educacional e a necessária participação dos sujeitos para sua concretização dependem da concepção que subjaz à gestão democrática da educação, princípio revestido de aprendizado no dia a dia e luta constante daqueles que acreditam na educação brasileira.

Em síntese, depreende-se que, enquanto Documento, o PME em foco pretende ser uma política educacional de caráter estatal, fundamentado na gestão democrática da educação, portanto, coloca a participação como princípio fundante para sua realização. No entanto, ao analisar seus desdobramentos, ficou explícito que tal concepção, na prática, ainda é o horizonte.

Em suma, está perceptível o distanciamento entre a sociedade política e a sociedade civil desde o processo de elaboração do PME até o presente momento, sua implementação. Entretanto, percebe-se, também, a resistência política da sociedade civil, que embora sem êxito em várias batalhas empreendidas, ainda assim, a luta da militância tem surtido efeitos no embate político pela garantia dos direitos que, seguramente, se assegurados podem fazer a diferença em relação a tão almejada educação de qualidade social.

\section{Referências}

ARANDA, F. P. N. A valorização docente na formulação do Plano Municipal de Educação de Dourados-MS (2015-2025). 2018. 182 f. Dissertação em Educação. Universidade Federal da Grande Dourados, Dourados, 2018.

AZEVEDO, J. M. L. de. A educação como política pública. Campinas, Autores Associados, 1997. Coleção Polêmicas do nosso tempo: v. 56. 
BORDIGNON, G. O Planejamento Educacional no Brasil. Fórum Nacional de Educação. 2011. Disponível em: <http://fne.mec.gov.br/images/pdf/planejamento_educacional_brasil.pdf $>$. Acesso em: 29 out. 2017.

BRASIL. Lei $N^{0} 13.005$, de 25 de junho de 2014. Aprova o Plano Nacional de Educação. Brasil, 2014. Disponível em: <http://www.planalto.gov.br/ccivil_03/_ato2011 2014/2014/lei/113005.htm.> Acesso em: 18 set. 2017.

CURY, C. R. J. Planos Nacionais de Educação no Brasil. In: FERREIRA, E. B.; FONSECA, M. (Orgs.) Política e Planejamento educacional no Brasil do século 21. Brasília: Liber Livro, 2013. p. 25-34.

DOURADOS. Estórias de Dourados. Secretaria Municipal de Educação/ SEMED, nov./2002. Disponível em: <http://estoriasdedourados.blogspot.com. br/2009/10/marcelino-pires-fundador.html>. Acesso em: 17 maio 2017.

DOURADOS. Lei $n^{\circ} 3.904$ de 23 de junho de 2015, Aprova o Plano Municipal de Educação do Município de Dourados do Estado do Mato Grosso do Sul, e dá outras providências. Disponível em: <http://www.dourados.ms.gov.br/wp-content/uploads/2015/11/PME-Dourados-2015-Vers\%C3\%A3o-Final-1.pdf >. Acesso em: 29 out. 2017.

DOURADOS. Decreto ${ }^{\circ} 363$ de 05 de junho de 2017. "Dispõe sobre a nomeação da Comissão Municipal de Monitoramento e Avaliação do Plano Municipal de Educação de Dourados - CMMA-PME e Equipe Técnica e dá outras providências". Diário Oficial de Dourados. Ano XIX / No 4.469 - Suplementar. Poder Executivo, 07 de junho de 2017.

DOURADO, L. F. A escolha de dirigentes escolares: políticas e gestão da educação no Brasil. In: FERREIRA, N. S. C. (Org.). Gestão democrática da educação: atuais tendências, novos desafios. 3. ed. São Paulo: Cortez, 2001. p. 193-212.

DOURADO, L. F. Políticas e gestão da educação básica no Brasil: limites e perspectivas. Educ. Soc., Campinas, v. 28, n. 100, Especial, p. 921-946, out. 2007. Disponível em <http://www.cedes.unicamp.br〉. Acesso em: 18 dez. 2017. 
FONSECA, M.; FERREIRA, E. B. O planejamento das políticas educativas no Brasil e seus desafios atuais. PERSPECTIVA. Florianópolis, v. 29, n. 1, p. 69-96, jan./jun. 2011. Disponível em: <http://www.perspectiva.ufsc.br>. Acesso em: 18 dez. 2017. IBGE. Instituto Brasileiro de Geografia e Estatística. 2015. Disponível em: <2https://cidades.ibge.gov.br/brasil/ms/dourados.> Acesso em: 18 de nov. 2017.

LUCKESI, C. C. Planejamento e Avaliação na Escola: articulação e necessária determinação ideológica. 2010. [on-line]. Disponível em: <luckessi.pdf/html.> Acesso em: em 05 maio 2017.

MARTINS, P. S. A política das políticas educacionais e seus atores. Jornal de Políticas Educacionais, Curitiba, n. 15. p. 13-32 jan./jun. 2014. Disponível em:<http://www. jpe.ufpr.br/n15_2.pdf>. Acesso em: 09 jan. 2017.

MONLEVADE, J. A. C. de. A importância do Conselho Municipal de Educação na elaboração, implantação e acompanhamento da execução do Plano Municipal de Educação. Pró-Conselho, 2013. Disponível em: <http://www.deolhonosplanos. org.br/biblioteca>. Acesso em: 10 jan. 2018.

PALUMBO, D. J. A abordagem de política pública para o desenvolvimento político na América. In: SOUZA, E. C. B. M. de (Org). A avaliação e a formulação de políticas públicas em educação: leituras complementares. Brasília: MEC/UnB, 1998. p. 35-62.

SAVIANI, D. A educação na Constituição Federal de 1988: avanços no texto e sua neutralização no contexto dos 25 anos de vigência. RBPAE - v. 29, n.2, p. 207221, mai/ago. 2013.

SAVIANI, D. Sistema Nacional de Educação e Plano Nacional de Educação: Significado, Controvérsias e Perspectivas. Campinas: Autores Associados, 2014.

SIMTED/Dourados. Educadores(as) exigem que Prefeitura de Dourados realize proposta salarial concreta na reunião de negociação do próximo dia 11 de maio. 2018. Disponível em: <http://www.simted.org.br/noticias/educadores-exigem-que-prefeitura-realize-proposta-salarial-concreta $\rangle$. Acesso em: 19 maio 2018. 
SIMTED/Dourados. Após reunião com muitos embaraços entre governo e categorias, PCCR será retirado novamente da Câmara. 2017. Disponível em: <http://www.simted.org.br/noticias/apos-reuniao-com-muitos-embaracos-pccr-sera-retirado-novamente-da-camara >. Acesso em: 19 maio 2018.

SCHNECKENBERG, M. A Relação Entre Políticas Públicas de Reforma Educacional e a Gestão do Cotidiano Escolar. Em Aberto. Brasília, v. 17,n. 72, p. 113-124, fev/jun, 2000.

VIEIRA, Everaldo. Democracia e política social. São Paulo: Cortez, 1992.

VIEIRA, Juçara Dutra. O direito à educação e a valorização profissional: o papel do Estado e da sociedade. Revista Retratos da Escola, Brasília, v. 10, n. 18, p. 2535, jan./jun. 2016. Disponível em: <http://educacionpublica.org/wp-content/ uploads/2017/06/retratos_da_escola_18_2016.pdf >. Acesso em: 27 maio 2018.

Recebido: 29/04/2018

Received: 04/29/2018

Recibido: $2904 / 2018$

Aprovado: 22/05/2018 Approved: 05/22/2018 Aprobado: 22/05/2018 